\title{
Historical perspectives of The American Association for Thoracic Surgery: F. Griffith Pearson (1926-)
}

\author{
Andrew Pierre, MD, Vivek Rao, MD, PhD, and Shaf Keshavjee, MD
}

F. Griffith Pearson, the 79th president of The American Association for Thoracic Surgery (AATS), was born in Toronto on July 7, 1926. His relationship with the University of Toronto began at a very young age. He attended what was then an experimental school, the University of Toronto High School, which was associated with the university and physically on the campus. He was a very good hockey player during high school, playing left wing for the University of Toronto college team. Although his father practiced optometry, it was his high school science teacher, Dr Kroll, who encouraged him to go into medicine. Pearson originally approached his mentor with the idea of becoming a science teacher, but Dr Kroll convinced him that medicine offered a greater breadth of opportunities. He completed medical school at the University of Toronto and was the silver medalist in the class of 1949.

After his internship at the Toronto General Hospital, Pearson worked as a general practitioner in Port Colborne, Ontario, a small town near Niagara Falls. Here he had the opportunity to work with 2 local general surgeons, whom Dr Pearson remembers as role models for "patient care and caring." After a year, he returned to the University of Toronto, where he did research under Wilfred G. Bigelow (55th AATS president), studying hypothermia for cardiac surgery and the "mysteries of hibernation" in groundhogs, which he had to collect in the wild with the help of a professional trapper. Dr Pearson's first publication, "Physiologic Studies of the Groundhog (Marmota monax)," was published in the Canadian Journal of Medical Science in 1953.

Dr Pearson returned to general practice for the next 3 years in the small northern Ontario town of Wawa on the Lake Superior shore, a secluded town that once recorded a temperature of $-51^{\circ} \mathrm{C}$. At one time, the town had no roads in or out, which, as Dr Pearson notes, led to his becoming very independent and resourceful. For his first cesarean delivery, he administered the anesthetic himself and then performed the operation. During this time, Dr Pearson

From the Divisions of Thoracic and Cardiovascular Surgery, Toronto General Hospital, University of Toronto, Toronto, Ontario, Canada.

Disclosures: Authors have nothing to disclose with regard to commercial support.

Received for publication Sept 3, 2011; accepted for publication Sept 26, 2011; available ahead of print Oct 24, 2011.

Address for reprints: Andrew Pierre, MD, 9N-958, Toronto General Hospital, 200 Elizabeth St. Toronto, ON M5G 2C4, Canada (E-mail: Andrew.Pierre@uhn.on.ca). J Thorac Cardiovasc Surg 2013;146:1016-7

0022-5223/\$36.00

Copyright (C) 2013 by The American Association for Thoracic Surgery

doi:10.1016/j.jtcvs.2011.09.046 developed the sense of "comprehensive patient care" that he practiced throughout his career. In 1955, he returned to the University of Toronto to do a residency in general surgery, which he finished in 1958, earning the title Fellow of the Royal College of Physicians and Surgeons of Canada. During his general surgery residency, he was trained by Fred Kergin (47th AATS president) and Robert Janes (32nd AATS president).

In Toronto in the 1950s, pulmonary and esophageal surgery was performed by general surgeons interested in the chest, while Dr Bigelow was leading another group of general surgeons into the new field of cardiac surgery. Pearson decided to focus on general thoracic surgery and studied in England with Mr Ronald Belsey at the Frenchay Hospital in Bristol in 1959 and 1960 (Figure 1). After his overseas fellowship, Pearson returned to a faculty position at Toronto General Hospital. It was Mr Belsey who had the greatest influence on Pearson's thoracic practice. To this day, Pearson quotes Belsey, "The battlefields of surgery are littered with the remains of new operations, which foundered and perished in the follow-up clinic." Pearson was known for his careful follow-up of patients, even decades after their initial surgery, a trait he obtained from Belsey. Another "gift" from Mr Belsey was the hiatal hernia repair bearing his name, the Belsey mark IV. This became Dr Pearson's preferred approach for hiatal hernias, because, in his own words, it was the "most physiologic repair." Later, Pearson went on to combine the Belsey repair with a Collis gastroplasty to lengthen the esophagus in cases of acquired shortening, a technique referred to as a "Pearson repair" at units across North American run by former trainees of Dr Pearson.

In 1960, Dr Pearson travelled to Copenhagen to witness the early use of prolonged mechanical ventilation for respiratory failure during the polio epidemic. He also observed the devastating laryngeal and tracheal injuries resulting from endotracheal tubes and tracheostomy tubes. These experiences stimulated him to champion the first intensive care unit in Canada, the so-called "respiratory failure unit," and led to his research and clinical interest in tracheal resection and reconstruction. His travelling fellowships in England and Scandinavia sparked lifelong friendships and collaborations with surgeons from around the world, including Tony Lerut, Clement Hiebert, Marcel Savary, and many others. In his AATS presidential address in 1990, he used the aphorism "there are many ways to skin a cat" to describe how valuable it was to travel the world and learn novel ways to do the same thing, or a different thing, and to dispel local myths. Dr Pearson has continued to travel, 


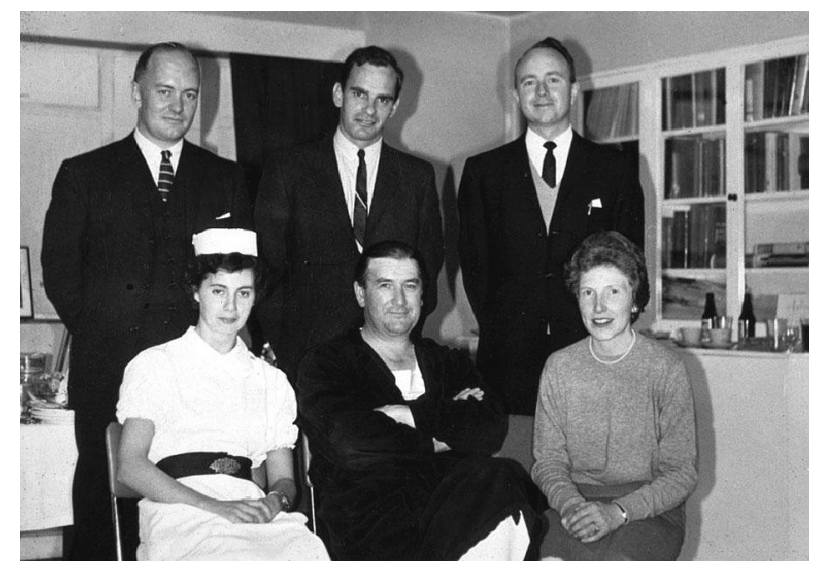

FIGURE 1. Pearson (standing, center back row) in 1960 at the end of his fellowship with Ronald Belsey (seated, center front row).

teach, observe, and learn from surgeons around the world even after retiring from active practice.

Through the years, Pearson advanced the discipline of thoracic surgery, and in 1968 a separate division of thoracic surgery was established at the University of Toronto under his leadership. Pearson introduced mediastinoscopy to North America in the early 1960s and demonstrated the importance of mediastinal staging for lung cancer, leading to a more rational approach to the diagnosis, staging, and treatment of the disease. In addition, along with his student Bob Ginsberg, Pearson helped establish in 1977 the multicenter National Institutes of Health Lung Cancer Study Group, which performed numerous important trials in lung cancer to which the University of Toronto was the greatest contributor of patients. During the 1960s and 1970s, Pearson continued to perform experimental studies of the trachea and its blood supply and to develop important principles for tracheal resection and reconstruction, including his technique for resection of the cricoid cartilage with preservation of the recurrent laryngeal nerves for subglottic stenosis, an operation that has come to be known as the Pearson operation. Dr Pearson, with Dr Hermes Grillo, is the father of modern tracheal surgery, having determined the upper limits of resection and reconstruction, prosthetic replacement, and the initial use of stents.

Pearson was asked one day at a conference after a particularly challenging tracheal resection, "How did you know that you would be able to bring the 2 ends of the trachea together after resecting half its length?" He replied honestly, "I didn't." Dr Pearson was a true pioneer-a pioneer who didn't necessarily always know what was beyond the horizon but was eager to go there and find out. It was fitting that his AATS presidential address was entitled, "Adventures in Surgery." Dr Pearson retired from active practice in 1999, ending his clinical career with 2

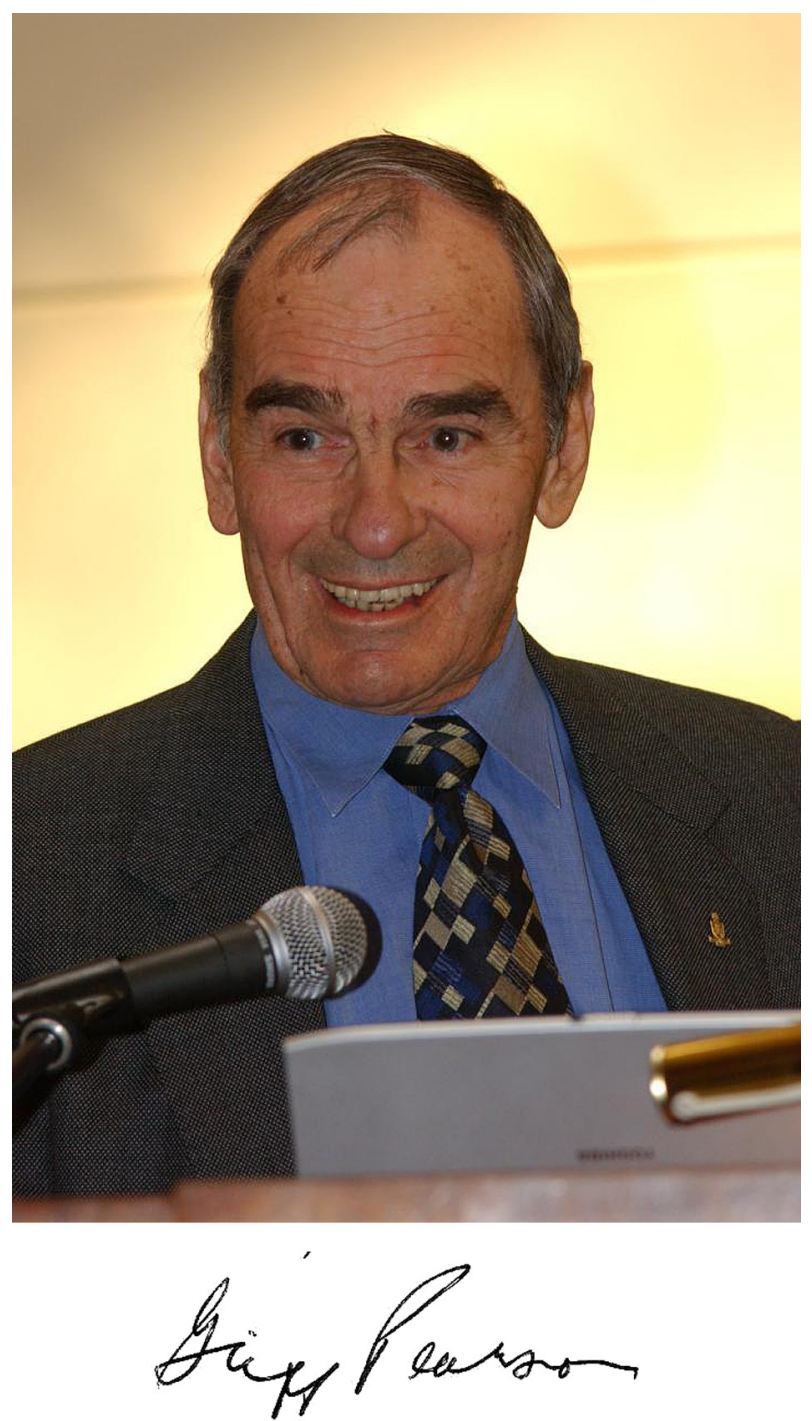

FIGURE 2. Pearson circa 2010.

Collis-Belsey procedures on his final day. Dr Pearson walked out of the operating room when he finished his cases that day and proclaimed prophetically, "I'm done here. Time to go fishing!"

But Dr Pearson was not done. He has continued to be a pioneer as a "surgeon in residence" in both Boston and Pittsburgh and as a keen observer, learner, and educator (Figure 2). Most would say his greatest contribution to thoracic surgery has been the influence he has had on young surgeons during the past 50 years and the influence he continues to have to this day. He draws us to this specialty, encourages us to improve the field, and leads by example. His influence spreads wide across North America and the world as his second- and even third-generation trainees carry on his teachings and traditions. 